\title{
DFT OPBE/TZVP Calculation of Molecular Structures of (5656) Macroheterocyclic Chelates of Double Charged 3d-Element Ions with 1,5,8,11-Tetraazacyclotetradecanetetrathione-2,3,9,10 and Its Dioxa- and Dithia Analogs
}

\author{
Oleg V. Mikhailov, ${ }^{a} @$ and Denis V. Chachkov ${ }^{\mathrm{b}}$ \\ ${ }^{a}$ Kazan National Research Technological University, 420015 Kazan, Russia \\ ${ }^{\mathrm{b}}$ Kazan Department of Joint Supercomputer Center of Russian Academy of Sciences - Branch of Federal State Institution \\ "Research Institute for System Analysis of Russian Academy of Sciences”, 420008 Kazan, Russia \\ @Corresponding author E-mail: olegmkhlv@gmail.com
}

\begin{abstract}
The calculation of the geometric parameters of the molecular structures of $M^{I I}$ macroheterocyclic chelates with tetradentate macrocyclic ligands formed as a result of template reactions in $M^{I I}$-dithiooxamide-formaldehyde, $M^{I I}$-dithiooxamide-formaldehyde-ammonia and $M^{I I}$-dithiooxamide-propandiol-1,3 systems $(\mathrm{M}=\mathrm{Mn}, \mathrm{Fe}, \mathrm{Co}, \mathrm{Ni}, \mathrm{Cu}$, $\mathrm{Zn})$, has been performed by using DFT method at the OPBE/TZVP level. The values of the bond lengths and bond angles in $\mathrm{MN}_{4}$ chelate nodes, bond angles in 5- and 6-membered metalchelate rings in the $M^{I I}$ chelates, have been presented. Also, the values of electric dipole moments and the standard thermodynamical parameters of formation (enthalpy, entropy and Gibbs free energy) of these chelates have been calculated.
\end{abstract}

Keywords: Macroheterocyclic metalchelate, 3d-element $\mathrm{M}^{\mathrm{II}}$ ion, molecular structure, DFT method.

\section{Расчет молекулярных структур (5656) макрогетероциклических хелатов Авухзарядных ионов 3d-элементов с 1,5,8,11-тетраазациклотетрадекан-тетратионом- 2,3,9,10 и его Аиокса- и Аитиааналогами методом DFT OPBE/TZVP}

О. В. Михайлов, ${ }^{a}$ А. В. Чачков ${ }^{\mathrm{b}}$

${ }^{a}$ Казанский национальный исследовательский технологический университет, 420015 Казань, Россия

${ }^{\mathrm{b}}$ Казанское отделение Межведомственного Суперкомпьютерного иентра Российской Академии Наук - филиал Федерального государственного учреждения «Федеральный научный изентр Научно-исследовательский институт системных исследований Российской Академии наук», 420008 Казань, Россия

@E-mail: olegmkhlv@gmail.com

Осуществлен квантовохимический расчет геометрических параметров молекулярньх структур (5656) макро-

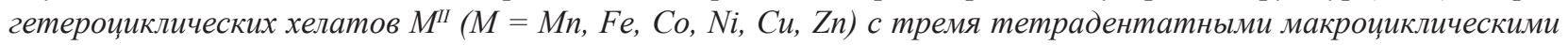
лигандами с использованием метода DFT OPBE/TZVP.

Ключевые слова: Макрогетероциклический металлохелат, ион $\mathrm{M}^{\mathrm{II}}$ 3d-элемента, метод функционала плотности (DFT). 


\section{Introduction}

Previously in ${ }^{[1]}$, the quantum-chemical calculations by DFT method of the some $\mathrm{M}^{\mathrm{II}}$ (5656)macrotetracyclic metalchelates with 1,8-dioxa-3,6,10,13-tetraazacyclotetradecanetetrathione-4,5,11,12 where $\mathrm{M}=\mathrm{Mn}, \mathrm{Fe}, \mathrm{Co}, \mathrm{Ni}, \mathrm{Cu}$, $\mathrm{Zn}$, that were formed in template reaction (1), were carried out.

$$
\mathrm{M}_{2}\left[\mathrm{Fe}(\mathrm{CN})_{6}\right]+4 \mathrm{H}_{2} \mathrm{~N}-\|_{\mathrm{S}}^{\mathrm{C}}-\mathrm{C}_{2}-\mathrm{NH}_{2}+8 \underset{\|}{\mathrm{HCH}}+4 \mathrm{OH}^{-} \longrightarrow
$$

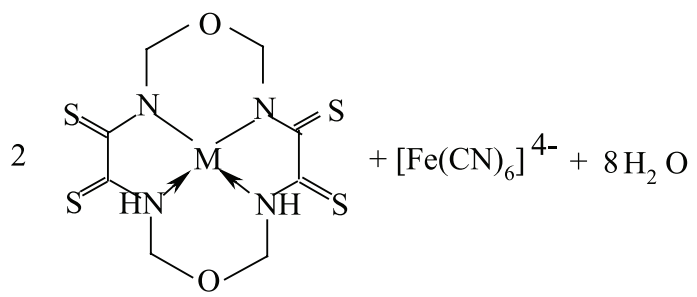

When formaldehyde in the reaction (1) is replaced with (formaldehyde + ammonia) composition, template reaction (2) with forming of $\mathrm{M}^{\mathrm{II}}$ metalchelates with 1,3,6,8,10,13-hexaazacyclotetradecanetetrathione-4,5,11,12 will takes place:

$$
\begin{aligned}
& \mathrm{M}_{2}\left[\mathrm{Fe}(\mathrm{CN})_{6}\right]+4 \mathrm{H}_{2} \mathrm{~N}-\mathrm{C}_{\mathrm{S}}^{\mathrm{C}}-\mathrm{C}-\mathrm{NH}_{2}+8 \underset{\|}{\mathrm{HCH}}+4 \mathrm{OH}^{-}+4 \mathrm{NH}_{3} \longrightarrow \\
& \text { ( }
\end{aligned}
$$

And, when formaldehyde in the reaction (1) is replaced with propandiol-1,3 $\mathrm{H}_{2} \mathrm{C}(\mathrm{OH})-\mathrm{CH}_{2}-\mathrm{CH}_{2}(\mathrm{OH})$, template reaction (3) with forming of $\mathrm{M}^{\mathrm{II}}$ metalchelates with 1,4,8,11-tetraazacyclotetradecanetetrathione-2,3,9,10 will occur:

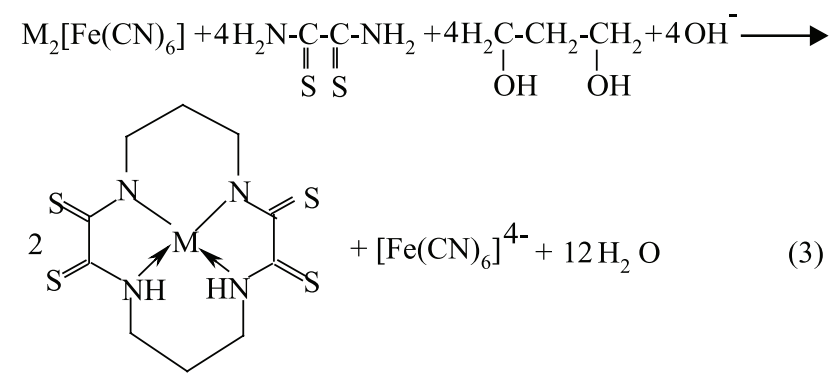

Each of macrocyclic ligands indicated above (the socalled chelant), contains a 14-membered macrocycle, two 5-membered and two 6-membered metal chelate cycles, and is coordinated to $\mathrm{M}^{\mathrm{II}}$ through four nitrogen atoms. In this connection, these (NNNN)donoratomic macrocyclic ligands may be considered as peculiar "predecessors" of such important ligands as porphyrins and phthalocyanines that, as known, play very significant role in live nature and human activities. On the other hand, according to the data, ${ }^{[2,3]}$ formation of such coordination compounds with these chelants is quite real in specific template processes proceeding in gelatin-immobilized matrix systems. Besides, in the first of these chelates, two $\mathrm{O}$ and four $\mathrm{N}$ heteroatoms, in the second ones, six $\mathrm{N}$ heteroatoms and in the third ones, only four $\mathrm{N}$ heteroatoms are in 14-membered "ring". Taking into account what has been said, it is rather interesting to get and analyze the objective data on structural and geometric parameters of these metal chelates using quantum-chemical calculation by DFT method. This calculation and comparison of its results for $\mathrm{M}^{\mathrm{II}}$ metalheterocyclic compounds with 1,4,8,11-tetraazacyclotetradecanetetrathione-2,3,9,10 (L1), 1,3,6,8,10,13-hexaazacyclotetradecanetetrathione-4,5,11,12 (L2) and 1,8-dioxa-3,6,10,13-tetraazacyclotetradecanetetrathione-4,5,11,12 (L3) will be just the subject of the given article.

\section{Method}

In order to carry out quantum-chemical calculations, the DFT OPBE/TZVP was applied. It combined the standard extended TZVP split-valence basis sets, described in papers ${ }^{[4,5]}$ and nonhybrid OPBE functional described in ${ }^{[6,7]}$. The choice of namely this quantum-chemical calculation method was connected with that according to the publications, ${ }^{[7-11]}$ in the case of $3 \mathrm{~d}$-element complexes, it gives more accurate ratio of the high-spin state energy stability to the low-spin one as compared to the most popular B3LYP method which was used in the our previous article. ${ }^{[1]}$ At the same time, DFT method accurately characterizes the basic geometric parameters of the molecular structures of the indicated compounds. The calculations were performed using the Gaussian09 program. ${ }^{[12]}$ As in previous articles, ${ }^{[1,13,14]}$ the correspondence of the obtained stationary points to the energy minima in all cases was proved by the calculation of the second energy derivatives in coordinates of atoms. Thus, all the equilibrium structures, corresponding to the minimum points on the potential energy surfaces, only had real values of frequencies. Calculation of molecular structure parameters in the multiplicity other than 1, has always held an unrestricted method (UHF); when multiplicity 1 - a restricted method (RHF). Standard thermodynamical parameters of formation, namely enthalpy $\Delta H_{f, 298}^{0}$, entropy $S_{f, 298}^{0}$ and Gibbs energy $\Delta G_{f, 298}^{0}$ were calculated according to method described in ${ }^{[15]}$.

\section{Results and Discussion}

Chelates with 1,4,8,11-tetraazacyclotetradecanetetrathione- 2,3,9,10, L1. According to our calculations, the ground state of the $\mathrm{MnL1}$ chelate with this macrocyclic ligand is a spin sextet and it is high-spin complex. For the FeL1 chelate, a ground state is spin triplet and it occupies an intermediate position between the low-spin and high-spin complexes. The ground states for the CoL1 and NiL1 chelates are a spin doublet and a spin singlet, respectively, so both of them are low-spin. As for the CuL1 and ZnL1 chelates, spin doublet and singlet, respectively, are their ground states in full agreement with theoretical expectations. Besides, the energy difference of structures with spin multiplicity (which is different from the ground state multiplicity) [quartet in the MnL1, quintet in the FeL1, quartet in the CoL1, triplet in the NiL1, quartet in the CuL1 and triplet in the ZnL1] 
is $20.2,24.2,51.4,68.8,71.9$ and $62.3 \mathrm{~kJ} / \mathrm{mol}$ respectively. As may be seen from these data, in the most cases, there is a very negligible (more than $25 \mathrm{~kJ} / \mathrm{mol}$ ) energy difference between the ground and the nearest different from it in spin multiplicity excited states; it is only less than this value in the case of the MnL1 and FeL1 chelates.

It should be noted at once that, contrary to theoretical expectations, all chelates indicated with 1,4,8,11-tetraazacyclotetradecanetetrathione-2,3,9,10 under examination are non-coplanar; moreover, the degree of their deviation from co-planarity is too big. It is noteworthy that $\mathrm{MN}_{4}$ chelate nodes as well as all 5-numbered and 6-numbered chelate rings are non-coplanar, too. In this connection, for all these coordination compounds, rather high values of the electric dipole moment $(\mu)$ can be expected. According to OPBE/TZVP calculation method data, values of $\mu$ for M(II) chelates with the such a liland are rather considerably and are 4.15, 5.80, 5.94, 5.73, 5.34 and 4.80 Debye units for the $\mathrm{Mn}^{\mathrm{II}}$, $\mathrm{Fe}^{\mathrm{II}}, \mathrm{Co}^{\mathrm{II}}, \mathrm{Ni}^{\mathrm{II}}, \mathrm{Cu}^{\mathrm{II}}$ and $\mathrm{Zn}^{\mathrm{II}}$ chelates respectively; as can be seen, these results fully confirms these expectations.

The values of the bond lengths and bond angles in $\mathrm{MN}_{4}$ chelate nodes, bond angles in 5- and 6-membered metalchelate rings in the $\mathrm{M}^{\mathrm{II}}$ chelates with 1,4,8,11-tetraazacyclotetradecanetetrathione-2,3,9,10 indicated above, have been presented in Table 1. Molecular structures of these compounds are outwardly very similar to each other; some of them are shown in Figure 1. All they have $C_{s}$ symmetry group with one plane symmetry and either pyramidal (MnL1, ZnL1) or quasi-planar (FeL1, CoL1, NiL1, CuL1) coordination of the donor centers of the ligand to the central atom. [The sum of the bond angles N1M1N2, N2M1N3, N3M1N4 and $\mathrm{N} 5 \mathrm{M} 1 \mathrm{~N} 2$ formed between the donor nitrogen atoms and $\mathrm{M}$ $(\boldsymbol{B A S})$ is $340.6^{\circ}$ in the case of MnL1, 356.3 - in the case of FeL1, 358. $6^{\circ}-\operatorname{CoL1}, 358.7^{\circ}-\mathrm{NiL1}, 356.2^{\circ}-\mathrm{CuL1}$ and $352.2^{\circ}-\mathrm{ZnL1}$. It should be noted, too, that only two of the indicated bond angles, namely N2M1N3 and N4M1N1, are equal to each other (Table 1). It is curious in this respect that the non-bond angles sum, N1N2N3, N2N3N4, N3N4N1, and N4N1N2 (NBAS) in all of the complexes is exactly $360.0^{\circ}$; hence, the group consisting of four donor nitrogen atoms is strictly planar. In five out of the six complexes, these angles are equal in pairs, namely, (N1N2N3) and (N4N1N2), $(\mathrm{N} 2 \mathrm{~N} 3 \mathrm{~N} 4)$ and $(\mathrm{N} 3 \mathrm{~N} 4 \mathrm{~N} 1)$, while in the $\mathrm{Cu}^{\mathrm{II}}$ chelate, all of these angles $\left(90^{\circ}\right)$ are exactly equal (Table 1$)$.
As can be seen from Table 1, the $\mathrm{M}-\mathrm{N}$ bond lengths in the metal chelates with 1,4,8,11-tetraazacyclotetradecanetetrathione-2,3,9,10 do not coincide with one another; the shortest $\mathrm{M}-\mathrm{N}$ lengths are noted for the $\mathrm{Ni}^{\mathrm{II}}$ chelate, while the longest ones are in the $\mathrm{Mn}^{\mathrm{II}}$ chelate. In the $\mathrm{Mn}-\mathrm{Zn}$ series, these bond lengths decrease on going from $\mathrm{Mn}$ to $\mathrm{Ni}$ and increase on going from $\mathrm{Ni}$ to $\mathrm{Zn}$. It is noteworthy that the M1-N3 and M1-N4 bond lengths decrease in this series on going from $\mathrm{Mn}$ to $\mathrm{Fe}$, from $\mathrm{Co}$ to $\mathrm{Ni}$, and from $\mathrm{Cu}$ to $\mathrm{Zn}$, while on going from $\mathrm{Fe}$ to $\mathrm{Co}$ and from $\mathrm{Ni}$ to $\mathrm{Cu}$ they decrease. In each of the considered metal chelates, the $\mathrm{M}-\mathrm{N}$ bond lengths are equal in pairs, namely, M1N1 and M1N2, and M1N3 and M1N4. A similar situation is observed for $\mathrm{C}-\mathrm{N}, \mathrm{C}-\mathrm{C}$, and $\mathrm{C}=\mathrm{S}$ bond lengths, in particular, for $\mathrm{N} 1 \mathrm{C} 5$ and $\mathrm{C} 6 \mathrm{~N} 2, \mathrm{C} 8 \mathrm{C} 9$ and $\mathrm{C} 9 \mathrm{C} 7$, and $\mathrm{C} 1 \mathrm{~S} 4$ and $\mathrm{C} 4 \mathrm{~S} 3$. The degree of deviation from planarity of each 5-membered metal chelate ring is rather large: the bond angle sums, $\mathbf{B} \mathbf{A} \mathbf{S}^{\mathbf{5 1}}$ and $\mathbf{B A S}^{52}$, are equal to each other and differ from the sum of the interior angles of a planar pentagon $\left(540^{\circ}\right)$ by at least $9.7^{\circ}$. Nevertheless, the valence angles in 5-membered cycles of these chelates coincide. The distortion of the 6-membered rings is much more pronounced [the bond angle sums $\mathbf{B} \mathbf{A} \mathbf{S}^{\mathbf{6 1}}$ and $\mathbf{B} \mathbf{A} \mathbf{S}^{\mathbf{6 2}}$ in these rings differ from the sum of the interior angles of a planar hexagon $\left(720^{\circ}\right)$ by at least $30^{\circ}$. Unlike the 5-membered rings, the 6-membered rings in the same chelate are not identical (Table 1). Note in this connection that all these parameters depend little on the nature of the $\mathrm{M}^{\mathrm{II}}$ metal ion.

The values of the key thermodynamic parameters of the $\mathrm{M}^{\mathrm{II}}$ chelates with 1,4,8,11-tetraazacyclotetradecanetetrathione-2,3,9,10 under examination (namely, enthalpy, entropy and Gibbs energy of formation in gas phase) are presented in Table 2. As can be seen from it, all these parameters for each of the given chelates are positive; moreover, they are very significant in absolute.

Chelates with 1,3,6,8,10,13-hexaazacyclotetradecanetetrathione-4,5,11,12, L2. As in the case of ML1 chelates with 1,4,8,11-tetraazacyclotetradecanetetrathione-2,3,9,10, the ground state of the $\mathbf{M n L 2}$ chelate with ligand under consideration is a spin sextet and it is high-spin complex. For the FeL2 chelate, a ground state is spin triplet and it occupies an intermediate position between the low-spin and high-spin complexes, too. The ground states for the CoL2 and NiL2 chelates are a spin doublet and a spin singlet,

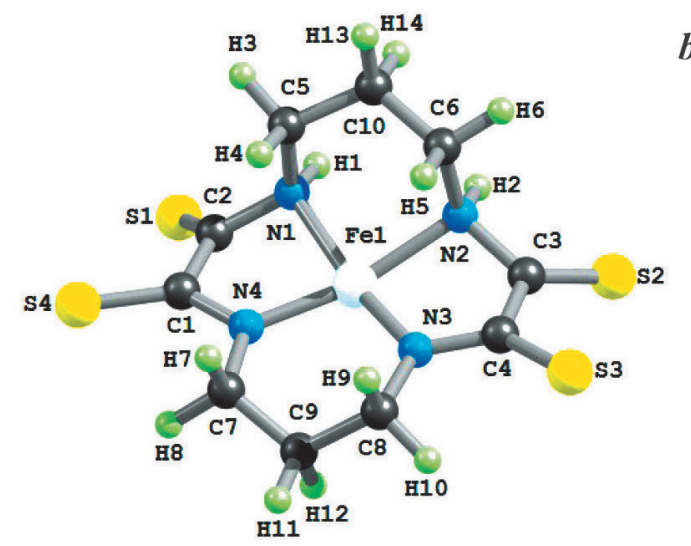

$\boldsymbol{b}$

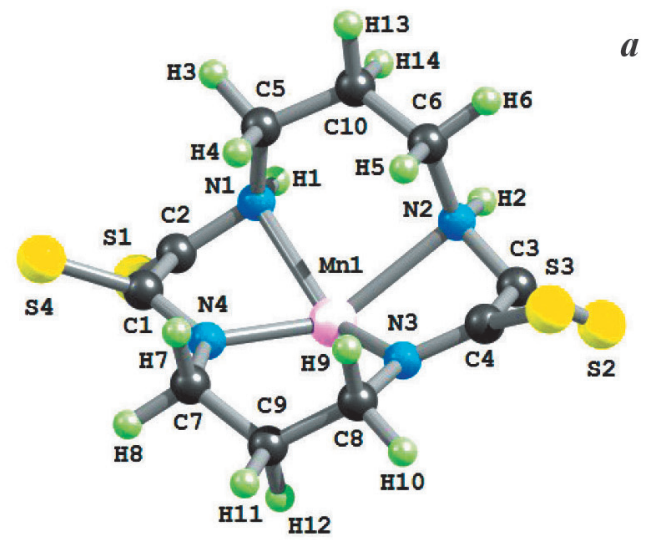

Figure 1. The molecular structures of the MnL1 (a) and FeL1 chelates (b) with 1,4,8,11-tetraazacyclotetradecanetetrathione-2,3,9,10. 
Table 1. Bond lengths, bond angles in chelate node and bond angles in metalchelate rings in the ML1 complexes of $3 d$-element with 1,4,8,11-tetraazacyclotetradecanetetrathione-2,3,9,10.

\begin{tabular}{|c|c|c|c|c|c|c|}
\hline $\mathrm{M}$ & $\mathrm{Mn}$ & $\mathrm{Fe}$ & Co & $\mathrm{Ni}$ & $\mathrm{Cu}$ & $\mathrm{Zn}$ \\
\hline \multicolumn{7}{|c|}{ Bond lengths in the $\mathrm{MN}_{4}$ chelate node, $\mathrm{pm}$} \\
\hline (M1N1) & 236.6 & 200.1 & 196.4 & 193.4 & 210.0 & 224.8 \\
\hline (M1N3) & 201.4 & 187.2 & 187.8 & 186.4 & 194.4 & 194.2 \\
\hline \multicolumn{7}{|c|}{ Bond angles in the $\mathrm{MN}_{4}$ chelate node (BAS), deg } \\
\hline (N1M1N2) & 83.2 & 89.3 & 90.4 & 90.3 & 90.7 & 85.7 \\
\hline (N2M1N3) & 79.0 & 84.3 & 84.5 & 84.5 & 82.6 & 81.1 \\
\hline (N3M1N4) & 99.4 & 98.4 & 99.0 & 99.4 & 100.3 & 104.3 \\
\hline (N4M1N1) & 79.0 & 84.3 & 84.5 & 84.5 & 82.6 & 81.1 \\
\hline BAS & 340.6 & 356.3 & 358.4 & 358.7 & 356.2 & 352.2 \\
\hline \multicolumn{7}{|c|}{ Non-bond angles in the $\mathrm{N}_{4}$ group of the $\mathrm{MN}_{4}$ chelate node (NBAS), deg } \\
\hline$(\mathrm{N} 2 \mathrm{~N} 3 \mathrm{~N} 6)$ & 89.3 & 90.2 & 90.8 & 91.1 & 90.0 & 90.1 \\
\hline (N3N6N5) & 90.7 & 89.8 & 89.2 & 88.9 & 90.0 & 89.9 \\
\hline$(\mathrm{N} 6 \mathrm{~N} 5 \mathrm{~N} 2)$ & 90.7 & 89.8 & 89.2 & 88.9 & 90.0 & 89.9 \\
\hline (N5N2N3) & 89.3 & 90.2 & 90.8 & 91.1 & 90.0 & 90.1 \\
\hline NBAS & 360.0 & 360.0 & 360.0 & 360.0 & 360.0 & 360.0 \\
\hline \multicolumn{7}{|c|}{ Bond angles in the 5-membered chelate ring $1\left(\mathbf{B A S}^{51}\right)$, deg } \\
\hline$(\mathrm{M} 1 \mathrm{~N} 2 \mathrm{C} 2)$ & 92.4 & 103.3 & 105.6 & 107.4 & 103.0 & 98.0 \\
\hline$(\mathrm{N} 1 \mathrm{C} 2 \mathrm{C} 1)$ & 112.7 & 111.3 & 111.0 & 110.6 & 112.3 & 112.6 \\
\hline$(\mathrm{C} 2 \mathrm{C} 1 \mathrm{~N} 4)$ & 110.4 & 110.8 & 110.5 & 110.7 & 111.5 & 110.7 \\
\hline (C1N4M1) & 115.7 & 116.0 & 116.6 & 117.1 & 116.0 & 117.2 \\
\hline (N4M1N1) & 79.0 & 84.3 & 84.5 & 84.5 & 82.6 & 81.1 \\
\hline BAS $^{51}$ & 510.2 & 525.7 & 528.2 & 530.3 & 525.3 & 519.6 \\
\hline \multicolumn{7}{|c|}{ Bond angles in the 6-membered chelate ring $1\left(\mathbf{B A S}^{61}\right)$, deg } \\
\hline (M1N1C5) & 104.0 & 102.0 & 102.5 & 104.1 & 100.2 & 101.2 \\
\hline$(\mathrm{N} 1 \mathrm{C} 5 \mathrm{C} 10)$ & 112.9 & 110.9 & 110.9 & 110.8 & 112.1 & 112.5 \\
\hline$(\mathrm{C} 5 \mathrm{C} 10 \mathrm{C} 6)$ & 117.7 & 116.8 & 117.0 & 116.5 & 117.7 & 117.7 \\
\hline$(\mathrm{C} 10 \mathrm{C} 6 \mathrm{~N} 2)$ & 112.9 & 110.9 & 110.9 & 110.8 & 112.1 & 112.5 \\
\hline$(\mathrm{C} 6 \mathrm{~N} 2 \mathrm{M} 1)$ & 104.0 & 102.0 & 102.5 & 104.1 & 100.2 & 101.2 \\
\hline (N2M1N1) & 83.2 & 89.3 & 90.4 & 90.3 & 90.7 & 85.7 \\
\hline $\mathrm{BAS}^{61}$ & 634.7 & 631.9 & 634.2 & 636.6 & 633.0 & 630.8 \\
\hline \multicolumn{7}{|c|}{ Bond angles in the 6-membered chelate ring $2\left(\mathbf{B A S}^{62}\right)$, deg } \\
\hline (M1N4C7) & 121.0 & 125.4 & 124.5 & 124.5 & 122.0 & 119.1 \\
\hline (N4C7C9) & 112.6 & 112.1 & 112.3 & 112.4 & 112.4 & 112.6 \\
\hline (C7C9C8) & 117.8 & 115.1 & 114.8 & 114.5 & 116.7 & 118.0 \\
\hline (C9C8N3) & 112.6 & 112.1 & 112.3 & 112.4 & 112.4 & 112.6 \\
\hline (C8N3M1) & 121.0 & 125.4 & 124.5 & 124.5 & 122.0 & 119.1 \\
\hline (N3M1N4) & 99.4 & 98.4 & 99.0 & 99.4 & 100.3 & 104.3 \\
\hline $\mathrm{BAS}^{62}$ & 684.4 & 688.5 & 687.4 & 687.7 & 685.8 & 685.7 \\
\hline
\end{tabular}

Table 2. Enthalpy $\Delta H_{f, 298}^{0}$, entropy $S_{f, 298}^{0}$ and Gibbs energy $\Delta G_{f, 298}^{0}$ of the various ML1 chelates with 1,4,8,11-tetraazacyclotetradecanetetrathione-2,3,9,10 in gas phase.

\begin{tabular}{cccc}
\hline $\mathrm{M}$ & $\Delta H_{f, 298}^{0}, \mathrm{~kJ} / \mathrm{mol}$ & $S_{f, 298}^{0}, \mathrm{~J} / \mathrm{mol} \cdot \mathrm{K}$ & $\Delta G_{f, 298}^{0}, \mathrm{~kJ} / \mathrm{mol}$ \\
\hline $\mathrm{Mn}$ & 490.8 & 740.1 & 487.5 \\
$\mathrm{Fe}$ & 243.9 & 762.5 & 235.5 \\
$\mathrm{Co}$ & 394.4 & 735.6 & 392.7 \\
$\mathrm{Ni}$ & 431.9 & 732.4 & 432.0 \\
$\mathrm{Cu}$ & 424.8 & 727.6 & 426.2 \\
$\mathrm{Zn}$ & 552.0 & 739.0 & 551.0 \\
\hline
\end{tabular}


respectively, and, hence, both they are low-spin complexes. In the case of $\mathrm{CuL2}$ and $\mathrm{ZnL2}$ chelates, spin doublet and singlet, respectively, are their ground states in full agreement with theoretical expectations. Besides, the energy difference of structures with spin multiplicity which is different from the ground state one [quartet in the case of $\mathbf{M n L 2}$, quintet in the case of FeL2, quartet in the CoL2, triplet in the NiL2, quartet in the CuL2 and triplet in the $\mathrm{ZnL2}]$ is $30.9,12.7$, 48.0, 66.8, 71.0 and $60.5 \mathrm{~kJ} / \mathrm{mol}$, respectively. Except only for a FeL2 chelate, energy difference between the ground and the nearest different from it in spin multiplicity excited states a very negligible (more than $25 \mathrm{~kJ} / \mathrm{mol}$ ). In the case indicated, in principle, spin isomerism (triplet - quintet) is possible.

All $\mathrm{M}^{\mathrm{II}}$ chelates with 1,3,6,8,10,13-hexaazacyclotetra decanetetrathione-4,5,11,12 are also non-coplanar; moreover, the degree of deviation from co-planarity of them is more than one of chelates with 1,4,8,11-tetraazacyclotetradecanetetrathione-2,3,9,10. Despite this, all they like ML1 chelates, have $C_{s}$ symmetry group with one plane symmetry. $\mathrm{MN}_{4}$ chelate nodes as well as all 5-membered and 6-membered chelate rings in complexes under examination are noncoplanar, too. The values of the electric dipole moment $(\mu)$ for these chelates are rather considerably [3.51, 5.66, 5.91, 5.82, 5.32 and 4.36 Debye units for the MnL2, FeL2, CoL2, NiL2, CuL2 and ZnL2 chelates, respectively]. However, in the most cases (excepting NiL2 complex) they are lesser than $\mu$ values for similar ML1 chelates with 1,4,8,11-tetraazacyclotetradecane-tetrathione-2,3,9,10. Calculated values of the bond lengths and bond angles in $\mathrm{MN}_{4}$ chelate nodes, bond angles in 5- and 6-membered metal chelate rings for all these chelates are given in Table 3. Molecular structures of some of them are shown in Figure 2. In complete correspondence with theoretical expectations, the group of the four nitrogen

Table 3. Bond lengths, bond angles in chelate node and bond angles in metalchelate rings in the ML2 chelates of $3 d$-element with 1,3,6,8,10,13-hexaazacyclotetradecanetetrathione-4,5,11,12.

\begin{tabular}{|c|c|c|c|c|c|c|}
\hline $\mathrm{M}$ & $\mathrm{Mn}$ & $\mathrm{Fe}$ & Co & $\mathrm{Ni}$ & $\mathrm{Cu}$ & $\mathrm{Zn}$ \\
\hline \multicolumn{7}{|c|}{ Bond lengths in the $\mathrm{MN}_{4}$ chelate node, $\mathrm{pm}$} \\
\hline (M1N1) & 243.3 & 201.2 & 197.1 & 194.2 & 212.2 & 229.6 \\
\hline (M1N3) & 200.9 & 187.1 & 186.9 & 185.8 & 194.7 & 194.3 \\
\hline \multicolumn{7}{|c|}{ Bond angles in the $\mathrm{MN}_{4}$ chelate node (BAS), deg } \\
\hline$(\mathrm{N} 1 \mathrm{M} 1 \mathrm{~N} 2)$ & 83.5 & 91.2 & 93.1 & 92.4 & 92.4 & 85.7 \\
\hline (N2M1N3) & 75.3 & 82.9 & 83.2 & 83.7 & 81.3 & 78.9 \\
\hline (N3M1N4) & 102.6 & 97.9 & 99.0 & 98.7 & 99.9 & 104.9 \\
\hline (N4M1N1) & 75.3 & 82.9 & 83.2 & 83.7 & 81.3 & 78.9 \\
\hline BAS & 336.7 & 354.9 & 358.5 & 358.5 & 354.9 & 348.4 \\
\hline \multicolumn{7}{|c|}{ Non-bond angles in the $\mathrm{N}_{4}$ group (NBAS), deg } \\
\hline (N1N2N3) & 88.9 & 89.4 & 89.8 & 90.2 & 89.1 & 89.6 \\
\hline (N2N3N4) & 91.1 & 90.6 & 90.2 & 89.8 & 90.9 & 90.4 \\
\hline (N3N4N1) & 91.1 & 90.6 & 90.2 & 89.8 & 90.9 & 90.4 \\
\hline$(\mathrm{N} 4 \mathrm{~N} 1 \mathrm{~N} 2)$ & 88.9 & 89.4 & 89.8 & 90.2 & 89.1 & 89.6 \\
\hline NBAS & 360.0 & 360.0 & 360.0 & 360.0 & 360.0 & 360.0 \\
\hline \multicolumn{7}{|c|}{ Bond angles in the 5-membered chelate ring $1\left(\mathbf{B A S}^{51}\right)$, deg } \\
\hline (M1N1C2) & 96.6 & 106.1 & 109.4 & 109.4 & 104.8 & 99.3 \\
\hline$(\mathrm{N} 1 \mathrm{C} 2 \mathrm{C} 1)$ & 112.7 & 111.3 & 111.2 & 110.9 & 112.5 & 112.8 \\
\hline$(\mathrm{C} 2 \mathrm{C} 1 \mathrm{~N} 4)$ & 109.3 & 110.8 & 110.7 & 110.6 & 111.2 & 110.1 \\
\hline (C1N4M1) & 121.8 & 118.4 & 119.3 & 118.8 & 117.9 & 120.3 \\
\hline (N4M1N1) & 75.3 & 82.9 & 83.2 & 83.7 & 81.3 & 78.9 \\
\hline $\mathrm{BAS}^{51}$ & 515.7 & 529.5 & 533.8 & 533.4 & $\mathbf{5 2 7 . 7}$ & 521.4 \\
\hline \multicolumn{7}{|c|}{ Bond angles in the 6-membered chelate ring $1\left(\mathbf{B A S}^{61}\right)$, deg } \\
\hline (M1N1C5) & 102.2 & 101.5 & 102.7 & 103.4 & 98.9 & 100.5 \\
\hline (N1C5N6) & 109.9 & 107.7 & 107.9 & 107.4 & 108.9 & 109.2 \\
\hline$(\mathrm{C} 5 \mathrm{~N} 6 \mathrm{C} 6)$ & 119.0 & 118.3 & 118.4 & 118.2 & 119.3 & 118.9 \\
\hline (N6C6N2) & 109.9 & 107.7 & 107.9 & 107.9 & 108.9 & 109.2 \\
\hline (C6N2M1) & 102.2 & 101.5 & 102.7 & 103.4 & 98.9 & 100.5 \\
\hline$(\mathrm{N} 2 \mathrm{M} 1 \mathrm{~N} 1)$ & 83.5 & 91.2 & 93.1 & 92.4 & 92.4 & 85.7 \\
\hline BAS $^{61}$ & 626.7 & 627.9 & 632.7 & 632.2 & 627.3 & 624.0 \\
\hline \multicolumn{7}{|c|}{ Bond angles in the 6-membered chelate ring $2\left(\mathbf{B A S}^{\mathbf{6 2}}\right)$, deg } \\
\hline (M1N4C7) & 114.4 & 133.2 & 122.2 & 122.7 & 119.7 & 115.4 \\
\hline (N4C7N5) & 108.5 & 109.2 & 109.6 & 109.8 & 109.7 & 109.1 \\
\hline (C7N5C8) & 118.7 & 115.3 & 115.0 & 114.7 & 117.0 & 118.7 \\
\hline (N5C8N3) & 108.5 & 109.2 & 109.6 & 109.7 & 109.7 & 109.1 \\
\hline (C8N3M1) & 114.4 & 123.2 & 122.2 & 122.7 & 119.7 & 115.4 \\
\hline (N3M1N4) & 102.6 & 97.9 & 99.0 & 98.7 & 99.9 & 104.9 \\
\hline BAS $^{62}$ & 667.1 & 678.0 & 677.6 & 678.4 & 675.7 & 672.6 \\
\hline
\end{tabular}



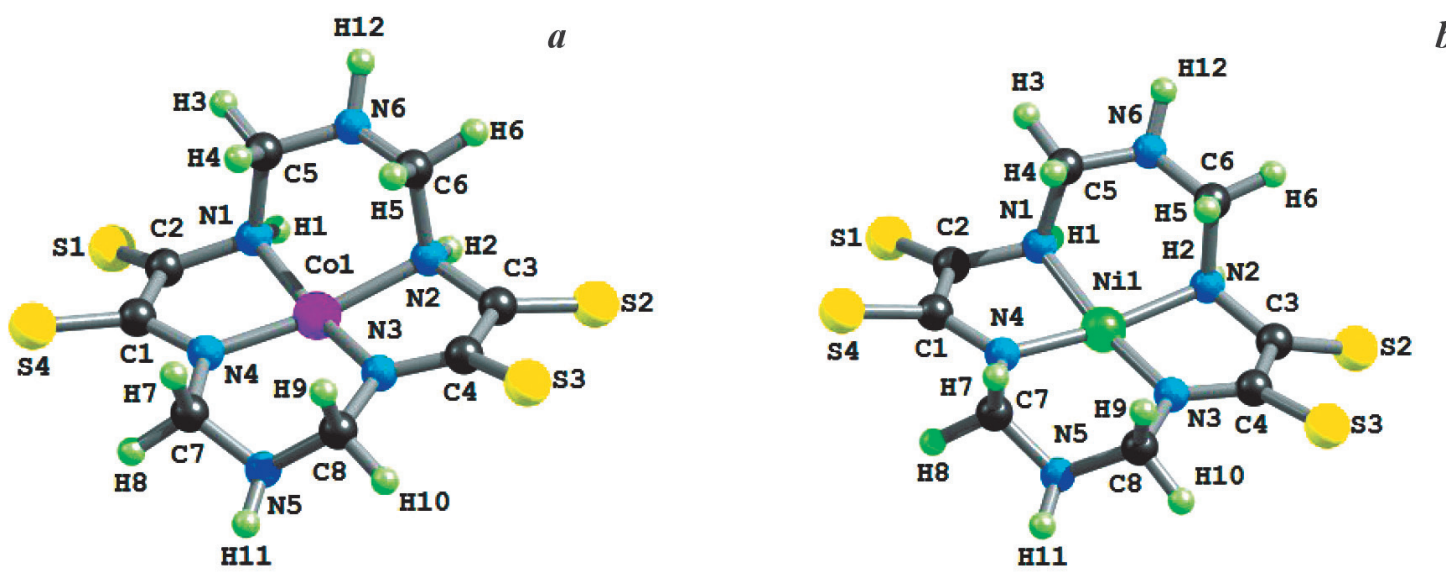

$b$

Figure 2. The molecular structures of the CoL2 (a) and NiL2 chelates (b) with 1,3,6,8,10,13-hexaazacyclotetradecanetetrathione-4,5,11,12.

atoms that form the $\mathrm{MN}_{4}$ chelate node is ideally planar in all ML2 chelates with 1,3,6,8,10,13-hexaazacyclotetradecanetetrathione-4,5,11,12 under examination [the sum of the (N1N2N3), (N2N3N4), (N3N4N1), and (N4N1N2) angles (NBAS) is exactly $360.0^{\circ}$. Nevertheless, the $\mathrm{MN}_{4}$ chelate node itself is planar in none of the chelates. Moreover, in the $\mathrm{Mn}^{\mathrm{II}}$ and $\mathrm{Zn}^{\mathrm{II}}$ chelates, the deviation of this node from co-planarity is rather significant [the sum of the (N1M1N2), $(\mathrm{N} 2 \mathrm{M} 1 \mathrm{~N} 3),(\mathrm{N} 3 \mathrm{M} 1 \mathrm{~N} 4)$, and (N4M1N1) bond angles ( $\boldsymbol{B} \boldsymbol{A S})$ is $336.7^{\circ}$ for $\mathrm{MnL2}, 354.9^{\circ}$ for FeL2 and $\mathrm{CuL} 2,358.5^{\circ}$ for CoL2 and NiL2, and $348.4^{\circ}$ for ZnL2]. In each of these chelates, the lengths of two of the four $\mathrm{M}-\mathrm{N}$ bond are the same; as for the distances between neighboring nitrogen atoms in chelate rings and the (NMN) bond angles, two of them are the same, while the other two are different (Table 3). Two additional 6-membered chelate rings formed upon the template cross-link and containing an $\mathrm{N}-\mathrm{C}-\mathrm{N}-\mathrm{C}-\mathrm{N}$ group do not lie in the same plane with the (NNNN) plane of the donor atoms even in the case of CoL2 and NiL2 chelates with a structure relatively close to planar. The deviation for each ring in each complex is different. The bond angle sums in these six-numbered cycles $\mathbf{B} \mathbf{A} \mathbf{S}^{61}$ and $\mathbf{B} \mathbf{A} \mathbf{S}^{62}$ differ significantly from the sum of the interior angles in a planar hexagon $\left(720^{\circ}\right)$. These sums depend only slightly on the nature of the $3 d$ metal $\mathrm{M}$, but differ rather strongly in the same chelate $\left(626.7^{\circ}\right.$ and $667.1^{\circ}$ for MnL2, $627.9^{\circ}$ and $678.0^{\circ}$ for FeL2, $632.7^{\circ}$ and $677.6^{\circ}$ for $\mathrm{CoL} 2,632.2^{\circ}$ and $678.4^{\circ}$ for NiL2, $627.3^{\circ}$ and $675.7^{\circ}$ for $\mathrm{CuL2}$, and $624.0^{\circ}$ and $672.1^{\circ}$ for $\mathrm{ZnL2}$ chelate, respectively). Both 5-membered rings in the ML2 metal chelates under consideration are also nonplanar [the $\mathbf{B} \mathbf{A} \mathbf{S}^{\mathbf{5 1}}$ and $\mathbf{B} \mathbf{A} \mathbf{S}^{\mathbf{5 2}}$ in them are smaller than the sum of the interior angles of a planar pentagon $\left.\left(540^{\circ}\right)\right]$ and are identical each other. However, as distinct from the 6-membered rings, the 5-membered rings are almost identical (Table 3). All angles in these rings are different. It is interesting that in all these chelates, the N5 and N6 atoms, not bonded to the M atoms, are located on different sides of the plane formed by the N1, N2, N3, and N4 donor atoms.

The values of the key thermodynamic parameters of the examined metal complexes with 1,3,6,8,10,13-hexaazacyclotetradecanetetrathione-4,5,11,12 (standard enthalpy, entropy and Gibbs energy of formation) are shown in
Table 4. As can be seen, all of them are positive, as similar parameters of ML1 chelates with 1,4,8,11-tetraazacyclotetradecanetetrathione-2,3,9,10, and all they are very significant in absolute, too.

Table 4. Enthalpy $\Delta H_{f, 298}^{0}$, entropy $S_{f, 298}^{0}$ and Gibbs energy $\Delta G_{f, 298}^{0}$ of the various ML2 chelates with 1,3,6,8,10,13-hexaazacyclotetradecanetetrathione-4,5,11,12 in gas phase.

\begin{tabular}{cccc}
\hline $\mathrm{M}^{\mathrm{II}}$ & $\Delta H_{f, 298}^{0}, \mathrm{~kJ} / \mathrm{mol}$ & $S_{f, 298}^{0}, \mathrm{~J} / \mathrm{mol} \cdot \mathrm{K}$ & $\Delta G_{f, 298}^{0}, \mathrm{~kJ} / \mathrm{mol}$ \\
\hline $\mathrm{Mn}^{\mathrm{II}}$ & 398.9 & 747.5 & 412.8 \\
$\mathrm{Fe}^{\mathrm{II}}$ & 562.8 & 716.9 & 584.4 \\
$\mathrm{Co}^{\mathrm{II}}$ & 599.0 & 711.8 & 623.0 \\
$\mathrm{Ni}^{\mathrm{II}}$ & 593.3 & 708.1 & 618.3 \\
$\mathrm{Cu}^{\mathrm{II}}$ & 716.4 & 721.5 & 738.4 \\
$\mathrm{Zn}^{\mathrm{II}}$ & 586.8 & 729.0 & 609.1 \\
\hline
\end{tabular}

Chelates with 1,8-dioxa-3,6,10,13-tetraazacyclotetradecane-tetrathione-4,5,11,12, L3. For all ML3 chelates with this ligand, the same spin multiplicities of ground state that for similar $\mathrm{M}^{\mathrm{II}}$ complexes considered above, take place. The energy difference of structures with spin multiplicity different from the ground state multiplicity [quartet in the $\mathbf{M n L 3}$, quintet in the FeL3, quartet in the CoL3, triplet in the NiL3, quartet in the $\mathrm{CuL3}$ and triplet in the $\mathrm{ZnL3}$ ] is 25.3, 67.6, $60.7,70.3,68.7$ and $57.8 \mathrm{~kJ} / \mathrm{mol}$, respectively. Besides, in the all ML3 chelates with 1,8-dioxa-3,6,10,13-tetraazacyclotetra-decanetetrathione-4,5,11,12 energy difference between the ground and the nearest different from it in spin multiplicity excited states a very negligible (more than $25 \mathrm{~kJ} / \mathrm{mol}$ ).

All ML3 chelates of the given type as well as all chelates ML1 and ML2 are non-coplanar; in addition, the degree of deviation from co-planarity of ML3 is slightly lesser than one of chelates ML2 but more than one of chelates ML1. $\mathrm{MN}_{4}$ chelate nodes as well as all 5-numbered and 6-numbered chelate rings in ML3 are non-coplanar, too. Molecular structures of some of them are shown in Figure 3. Chelates ML3 as well as ML1 and ML2 ones, have also only one element of symmetry, namely symmetry flatness. The values of the electric dipole moment $(\mu)$ for complexes ML3 are rather considerably $(4.39,5.20,4.91,5.61,5.18$ and 
4.84 Debye units for the $\mathrm{Mn}^{\mathrm{II}}, \mathrm{Fe}^{\mathrm{II}}, \mathrm{Co}^{\mathrm{II}}, \mathrm{Ni}^{\mathrm{II}}, \mathrm{Cu}^{\mathrm{II}}$ and $\mathrm{Zn}^{\mathrm{II}}$ coordination compounds, respectively). Besides, in the most cases [excepting FeL3 and ZnL3 chelates] they are lesser than $\mu$ values for similar ML1 chelates. Calculated values of the bond lengths and bond angles in $\mathrm{MN}_{4}$ chelate nodes, bond angles in 5- and 6-membered metal chelate rings for all ML3 chelates are given in Table 5. As good is evident from the data presented in it, the structural features of ML3 chelates and the patterns of their change depending on the nature of $\mathrm{M}^{\mathrm{II}}$ is largely similar to the corresponding parameters for the chelates ML1 and ML2. In this connection, there is probably no need to dwell on this in more detail in the given article. It should be noted only in this connection that in the all ML3 chelates considered here, both 5-membered metalchelate rings are absolutely identically to each other whereas 6-membered rings very strongly differ among themselves. The values of the key thermodynamic parameters of the examined metalheterocyclic compounds with 1,8-dioxa3,6,10,13-tetraazacyclotetradecanetetrathione-4,5,11,12 (standard enthalpy, entropy and Gibbs energy of formation) are shown in Table 6 . As can be seen, all of them are positive, as similar parameters of complexes ML1, and almost all they

Table 5. Bond lengths, bond angles in chelate node and bond angles in metalchelate rings in the ML3 chelates of $3 d$-element with 1,8-dioxa3,6,10,13-tetraazacyclotetradecanetetrathione-4,5,11,12.

\begin{tabular}{|c|c|c|c|c|c|c|}
\hline $\mathrm{M}$ & $\mathrm{Mn}$ & $\mathrm{Fe}$ & Co & $\mathrm{Ni}$ & $\mathrm{Cu}$ & $\mathrm{Zn}$ \\
\hline \multicolumn{7}{|c|}{ Bond lengths in the $\mathrm{MN}_{4}$ chelate node, $\mathrm{pm}$} \\
\hline (M1N1) & 236.3 & 200.2 & 196.7 & 193.4 & 210.3 & 224.8 \\
\hline (M1N3) & 201.6 & 186.5 & 183.0 & 184.8 & 193.8 & 194.4 \\
\hline \multicolumn{7}{|c|}{ Bond angles in the $\mathrm{MN}_{4}$ chelate node (BAS), deg } \\
\hline (N1M1N2) & 83.8 & 91.1 & 90.2 & 92.5 & 92.1 & 86.1 \\
\hline (N2M1N3) & 77.5 & 83.2 & 84.4 & 84.2 & 82.1 & 80.3 \\
\hline (N3M1N4) & 96.9 & 96.4 & 97.8 & 97.6 & 98.1 & 101.4 \\
\hline (N4M1N1) & 77.5 & 83.2 & 84.4 & 84.2 & 82.1 & 80.3 \\
\hline BAS & 335.7 & 353.9 & 356.7 & 358.5 & 354.4 & 348.1 \\
\hline \multicolumn{7}{|c|}{ Non-bond angles in the $\mathrm{N}_{4}$ group (NBAS), deg } \\
\hline (N1N2N3) & 88.6 & 89.1 & 89.7 & 89.9 & 88.9 & 89.3 \\
\hline (N2N3N4) & 91.4 & 90.9 & 90.3 & 90.1 & 91.1 & 90.7 \\
\hline (N3N4N1) & 91.4 & 90.9 & 90.3 & 90.1 & 91.1 & 90.7 \\
\hline (N4N1N2) & 88.6 & 89.1 & 89.7 & 89.9 & 88.9 & 89.3 \\
\hline NBAS & 360.0 & 360.0 & 360.0 & 360.0 & 360.0 & 360.0 \\
\hline \multicolumn{7}{|c|}{ Bond angles in the 5-membered chelate ring $1\left(\mathbf{B} \mathbf{A} \mathbf{S}^{51}\right)$, deg } \\
\hline (M1N1C2) & 96.7 & 106.7 & 107.5 & 110.0 & 105.1 & 100.0 \\
\hline$(\mathrm{N} 1 \mathrm{C} 2 \mathrm{C} 1)$ & 112.5 & 111.1 & 110.8 & 110.9 & 112.5 & 112.4 \\
\hline$(\mathrm{C} 2 \mathrm{C} 1 \mathrm{~N} 4)$ & 110.1 & 110.9 & 110.7 & 110.9 & 111.5 & 110.5 \\
\hline (C1N4M1) & 118.8 & 118.6 & 118.8 & 119.0 & 117.5 & 118.8 \\
\hline (N4M1N1) & 77.5 & 83.2 & 84.4 & 84.2 & 82.1 & 80.3 \\
\hline $\mathrm{BAS}^{51}$ & 515.6 & 530.5 & 532.1 & 535.0 & 528.7 & 522.3 \\
\hline \multicolumn{7}{|c|}{ Bond angles in the 6-membered chelate ring $1\left(\mathbf{B A S}^{61}\right)$, deg } \\
\hline (M1N1C5) & 103.5 & 101.8 & 103.4 & 103.8 & 99.3 & 101.8 \\
\hline (N1C5O1) & 111.3 & 110.3 & 110.0 & 110.2 & 111.0 & 111.0 \\
\hline (C5O1C6) & 117.5 & 116.8 & 117.0 & 116.7 & 117.6 & 117.4 \\
\hline$(\mathrm{O} 1 \mathrm{C} 6 \mathrm{~N} 2)$ & 111.3 & 110.3 & 110.0 & 110.2 & 111.0 & 111.0 \\
\hline (C6N2M1) & 103.5 & 101.8 & 103.4 & 103.8 & 99.3 & 101.8 \\
\hline$(\mathrm{N} 2 \mathrm{M} 1 \mathrm{~N} 1)$ & 83.8 & 91.1 & 90.2 & 92.5 & 92.1 & 86.1 \\
\hline BAS $^{61}$ & 630.9 & 632.1 & 634.0 & 637.2 & 630.3 & 627.3 \\
\hline \multicolumn{7}{|c|}{ Bond angles in the 6-membered chelate ring $2\left(\mathbf{B} \mathbf{A} \mathbf{S}^{62}\right)$, deg } \\
\hline (M1N4C7) & 118.0 & 123.0 & 122.8 & 122.4 & 119.9 & 116.8 \\
\hline$(\mathrm{N} 4 \mathrm{C} 7 \mathrm{O} 2)$ & 110.8 & 111.2 & 111.5 & 111.5 & 111.4 & 111.0 \\
\hline$(\mathrm{C} 7 \mathrm{O} 2 \mathrm{C} 8)$ & 116.2 & 114.4 & 114.1 & 114.0 & 115.7 & 116.6 \\
\hline (O2C8N3) & 110.8 & 111.2 & 111.5 & 111.5 & 111.4 & 111.0 \\
\hline (C8N3M1) & 110.8 & 111.2 & 111.5 & 111.5 & 111.4 & 111.0 \\
\hline (N3M1N4) & 96.9 & 96.4 & 97.8 & 97.6 & 98.1 & 101.4 \\
\hline $\mathrm{BAS}^{62}$ & 670.7 & 679.2 & 680.4 & 679.4 & 676.4 & 673.6 \\
\hline
\end{tabular}


are very significant in absolute, too. The only exception is the value of $\Delta H_{f, 298}^{0}$ for the MnL3 complex (46.6 kJ/mol).

The macroheterocyclic compounds considered here, differ on chemical composition from each other only in that, in the complexes of type ML1 in both 6-membered metal chelate rings, methylene groups $\left(-\mathrm{CH}_{2}-\right)$ are, whereas in the complexes of type ML2, imino groups (-NH-) and in the complexes of type ML3, oxide (-O-) groups are. In this connection, it is interesting to take notice how structural parameters of these complexes will change with substitution of carbon atom to heteroatoms $\mathrm{N}$ and $\mathrm{O}$, respectively. The final part of the given paper will be devoted to consideration of this question, namely.

Table 6. Enthalpy $\Delta H_{f, 298}^{0}$, entropy $S_{f, 298}^{0}$ and Gibbs energy $\Delta G_{f, 298}^{0}$ of the various ML3 chelates with 1,8-dioxa-3,6,10,13-tetraazacyclotetradecanetetrathione- $4,5,11,12$ in gas phase.

\begin{tabular}{cccc}
\hline $\mathrm{M}^{\mathrm{II}}$ & $\Delta H_{f, 298}^{0}, \mathrm{~kJ} / \mathrm{mol}$ & $S_{f, 298}^{0}, \mathrm{~J} / \mathrm{mol} \cdot \mathrm{K}$ & $\Delta G_{f, 298}^{0}, \mathrm{~kJ} / \mathrm{mol}$ \\
\hline $\mathrm{Mn}^{\mathrm{II}}$ & 46.6 & 751.6 & 24.8 \\
$\mathrm{Fe}^{\mathrm{II}}$ & 201.9 & 727.4 & 185.9 \\
$\mathrm{Co}^{\mathrm{II}}$ & 228.9 & 721.5 & 215.4 \\
$\mathrm{Ni}^{\mathrm{II}}$ & 298.8 & 731.3 & 281.5 \\
$\mathrm{Cu}^{\mathrm{II}}$ & 228.2 & 718.0 & 215.8 \\
$\mathrm{Zn}^{\mathrm{II}}$ & 356.7 & 730.9 & 341.4 \\
\hline
\end{tabular}

As can be seen from comparison of the data presented in the Tables 1, 3 and 5, the dependences of structural parameters (bond lengths, bond angles, sums of bond angles etc.) for the same $\mathrm{M}^{\mathrm{II}}$, as a rule, have extreme nature. It is noteworthy that this extremum takes place practically always for complexes ML2 that contain N heteroatoms; besides, it may be a maximum as well as a minimum. Maximums, for example, are observed for M1N2 bond lengths for each $\mathrm{M}^{\mathrm{II}}$ considered. For example, in the case of $\mathrm{Mn}^{\mathrm{II}}$ - $236.6 \mathrm{pm}$ (in chelate ML1), $243.3 \mathrm{pm}$ (in chelate ML2) and $236.3 \mathrm{pm}$ (in chelate ML3). In the case of $\mathrm{Cu}^{\mathrm{II}}-$ 210.0 pm (ML1), 212.2 pm (ML2), 210.3 pm (ML3)], and, also, for M1N1 bonds in the $\mathrm{Ni}^{\mathrm{II}}$ complexes $(186.4,185,8$, $184.8 \mathrm{pm}$, respectively) and $\mathrm{Cu}^{\mathrm{II}}$ ones $(194.4,194,7,193.8$ $\mathrm{pm}$, respectively). Minima take place, among their number, for bond angles sums in the each of 6-membered rings $\mathbf{B A S}^{61}$ and $\mathbf{B} \mathbf{A} \mathbf{S}^{62}$ (which, as it was mentioned earlier by us, differ between themselves extremely noticeably) independently of $\mathrm{M}^{\mathrm{II}}$ nature. So, in the case of $\mathrm{Co}^{\mathrm{II}}$ for the $\mathbf{B A} \mathbf{S}^{61}$ is $634.2^{\circ}$

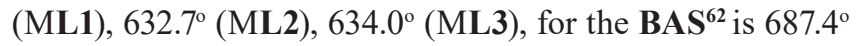
(ML1), $677.6^{\circ}(\mathrm{ML2}), 680.4^{\circ}$ (ML3). In the case of $\mathrm{Zn}^{\mathrm{II}}-$ $630.8^{\circ}$ (ML1), 624.0 (ML2), 627.3 (ML3); 685.7 (ML1),

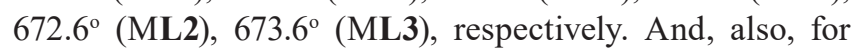
M1N1 bond lengths in $\mathrm{Mn}^{\mathrm{II}}$ complexes (201.4, 200,9, 201.6 pm, respectively) (see Tables 1, 3 and 5). It should be noticed in this connection that $\mathrm{C}-\mathrm{E}-\mathrm{C}$ bond angles values (where $\mathrm{E}$ is $\mathrm{C}$ in the ML1 chelates, $\mathrm{N}$ in the ML2 chelates, and $\mathrm{O}$ in the ML3 chelates) in the both 6-numbered metal chelate rings at the transition from complexes ML1 to ML3 chelates pass through a maximum. Among their number, in the case of $\mathrm{Fe}^{\mathrm{II}}$ for the first of these rings, these angles are $116.8^{\circ}$ (ML1), $118.3^{\circ}$ (ML2) and $116.8^{\circ}(\mathrm{ML3})$, for the second ones, are $115.1^{\circ}(\mathrm{ML1}), 115.3^{\circ}(\mathrm{ML2})$ and $114.4^{\circ}(\mathrm{ML3})$, in the case of $\mathrm{Ni}^{\mathrm{II}}-116.5^{\circ}(\mathrm{ML1}), 118.2^{\circ}(\mathrm{ML2})$ and $116.7^{\circ}(\mathrm{ML3}) ; 114.5^{\circ}$ (ML1), $114.7^{\circ}(\mathrm{ML2})$ and $114.0^{\circ}$ (ML3), respectively. At the same time, monotonous increase or, opposite, monotonous decrease occurs for separate structural parameters in the series of complexes ML1 - ML2 - ML3. The first of these variants, for example, occurs for change of bond angles sums in the both 5-numbered rings for five of the six $\mathrm{M}^{\mathrm{II}}$ considered here (exception is only $\mathrm{Co}^{\mathrm{II}}$ ). For example, in the case of $\mathrm{Fe}^{\mathrm{II}}$ both $\mathbf{B A S} \mathbf{S}^{51}$ and $\mathbf{B A S}{ }^{52}$ is $525.7^{\circ}$ (ML1), 529.5 (ML2), $530.5^{\circ}(\mathrm{ML3})$, in the case of $\mathrm{Ni}(\mathrm{II})-530.3^{\circ}$ (ML1), 533.4 (ML2), 535.0 $^{\circ}$ (ML3)]. The second variant takes place for change of bond angles in $\mathrm{MN}_{4}$ chelate node [for example, in the case of $\mathrm{Mn}^{\mathrm{II}} \boldsymbol{B} \boldsymbol{A S}$ is $340.6^{\circ}$ (ML1), 336.7 (ML2), $335.7^{\circ}$ (ML3), in the case of $\mathrm{Zn}^{\mathrm{II}}-352.2^{\circ}$ (ML1), $348.4^{\circ}$ (ML2), 348.1 ${ }^{\circ}$ (ML3)].

It is noteworthy that unlike $\mathrm{C}-\mathrm{E}-\mathrm{C}$ bond angles values in both 6-membered metal chelate rings ( $\mathrm{E}-\mathrm{C}, \mathrm{N}$ or $\mathrm{O})$, the C-E bond lengths at the transition from ML1 to ML3 monotonically decreasing. [So, in the case of $\mathrm{Co}^{\mathrm{II}}$ they are 152.7 , $143.3,140.0 \mathrm{pm}$ in the ring 1 and $151.8,143.9,139.6 \mathrm{pm}$ in the ring 2 , in the case of $\mathrm{Cu}^{\mathrm{II}}-152.5,143.2,139.9 \mathrm{pm}$ in the ring 1 and $152.4,144.1,140.3 \mathrm{pm}$ in the ring 2]. This circumstance may be connected with two factors. On the one hand, $\mathrm{C}$ atom radius is more than one of $\mathrm{N}$ and $\mathrm{O}$ atoms. On the other hand, with that, in the series of complexes ML1 - ML2 - ML3, decrease of numbers $\mathrm{H}$ atoms connected by chemi-
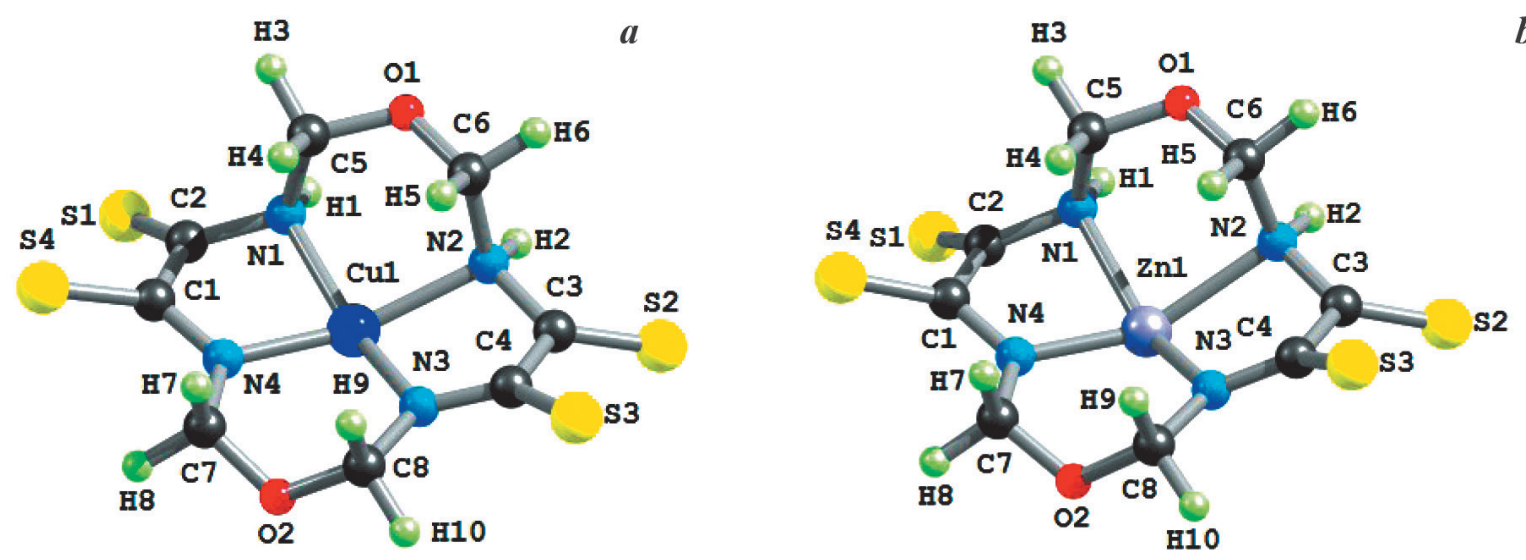

Figure 3. The molecular structures of the $\mathrm{CuL3}(a)$ and $\mathrm{ZnL3}$ complexes (b) with 1,8-dioxa-3,6,10,13-tetraazacyclotetradecanetetrathione-4,5,11,12. 
cal bonds with above-mentioned atoms in their 6-membered rings [from two in the complex ML1 $\left(-\mathrm{CH}_{2}-\right)$ to zero in the complex ML3 (-O-)] occurs. Sometimes, however, there are also cases when the values of the some structural parameter for the same $\mathrm{M}^{\mathrm{II}}$ does not practically depend on the type of complex. So, NBAS in the all without exception complexes under examination is equal $360.0^{\circ}$ (i.e. $\mathrm{N}_{4}$ atoms grouping is perfectly flat); bond angles sums $\boldsymbol{B} \boldsymbol{A S}$ in the $\mathrm{Ni}^{\mathrm{II}}$ complexes almost coincide with each other $\left[358.7^{\circ}\right.$ (ML1), 358.5 ${ }^{\circ}$ (ML2), 358.5 (ML3)]. C4S3 bond lengths in the $\mathrm{Mn}^{\mathrm{II}}$ and $\mathrm{Zn}^{\mathrm{II}}$ complexes are practically identical $(167.0 \mathrm{pm})$. And, that is typical, non-coplanarity of $\mathrm{MN}_{4}$ chelate node is pronounced in the most degree in the complexes of type ML3, non-coplanarity of 5-membered rings - in the complexes ML1 and non-coplanarity of 6-numbered rings - in the complexes ML2.

As to of standard thermodynamic parameters of formation of metal complexes ML1, ML2 and ML3, how it easy see when comparing the data in Tables 2, 4 and $6, \Delta H_{f, 298}^{0}$ and $\Delta G_{f, 298}^{0}$ values for complexes ML3 for all $\mathrm{M}^{\mathrm{II}}$ under examination are found to be considerably less than similar parameters for complexes ML1 and ML2. The most sharply this difference is expressed in the case of complexes of $\mathrm{Mn}^{\mathrm{II}}$, in which $\Delta H_{f, 298}^{0}$ are $490.8,398.9$ and $46.6 \mathrm{~kJ} / \mathrm{mol}, \Delta G_{f, 298}^{0}-$ 487.5, 412.8 and $24.8 \mathrm{~kJ} / \mathrm{mol}$ for complexes ML1, ML2 and ML3, respectively. Besides, the values of standard entropy of formation $S_{f, 298}^{0}$ of the all these coordination compounds differ between themselves in considerably lesser degree, and, as a rule, the least their values takes place in the case of complexes ML2. But whatever, $\Delta H_{f, 298}^{0}, S_{f, 298}^{0}$ and $\Delta G_{f, 298}^{0}$ for each of complexes under examination are positive, and it means that, under "traditional" complexing conditions (i.e., in solution or in solid phase), processes of their formation (1-3), likely to be thermodynamically forbidden. However, in the specific conditions that takes place during complexing in biopolymer-immobilized matrices, these reactions, in principle, would be able to be realized. ${ }^{[3,16]}$

\section{Conclusion}

As can be seen, all $3 d$-elements $\mathrm{M}^{\mathrm{II}}$ chelates with (5656) macroheterocyclic ligands - 1,4,8,11-tetraazacyclotetradecanetetrathione-2,3,9,10, 1,3,6,8,10,13-hexaazacyclotetradecanetetrathione-4,5,11,12 and 1,8-dioxa-3,6,10,13-tetraazacyclotetradecanetetrathione-4,5,11,12 that were considered in this paper, are on the whole non-coplanar. Besides, such a non-coplanarity takes place for almost all structural fragments of these compounds - for chelate nodes $\mathrm{MN}_{4}$ as well as and for each of the 5- and 6-membered chelate rings; the only exception is the grouping of four nitrogen atoms coordinated to $\mathrm{M}^{\mathrm{II}}$ ion. For all these chelates, positive and extremely high values of standard enthalpies $\left(\Delta H_{f, 298}^{0}\right)$ and standard Gibbs' energies of formation $\left(\Delta G_{f, 298}^{0}\right)$ are typical.
Acknowledgements. This paper was prepared with the Ministry of Education and Science of Russian Federation financial support (Project No. 4.1584.2014/K). All quantum chemical calculations were carried out in the Kazan Department of Joint Supercomputer Center of Russian Academy of Sciences - Branch of Federal State Institution "Scientific Research Institute for System Analysis of the Russian Academy of Sciences" (http://kbjscc.knc.ru), to which the authors are also grateful for the support rendered to them.

\section{References}

1. Chachkov D.V., Mikhailov O.V. Macroheterocycles 2009, 2, 271-274.

2. Mikhailov O.V. Rev. Inorg. Chem. 2010, 30, 199-273.

3. Mikhailov O.V. Inorg. Chim. Acta 2013, 394, 664-684.

4. Schaefer A., Horn H., Ahlrichs R. J. Chem. Phys. 1992, 97, 2571-2577.

5. Schaefer A., Huber C., Ahlrichs R. J. Chem. Phys. 1994, 100, 5829-5835.

6. Hoe W.-M., Cohen A., Handy N.C. Chem. Phys. Lett. 2001, 341, 319-328.

7. Perdew J.P., Burke K., Ernzerhof M. Phys. Rev. Lett. 1997, 78, 1396-1397.

8. Paulsen H., Duelund L., Winkler H., Toftlund H., Trautwein A.X. Inorg. Chem. 2001, 40, 2201-2203.

9. Swart M., Groenhof A.R., Ehlers A.W., Lammertsma K. $J$. Phys. Chem., A 2004, 108, 5479-5483.

10. Swart M., Ehlers A.W., Lammertsma K. Mol. Phys. 2004, 102, 2467-2474.

11. Swart M. Inorg. Chim. Acta 2007, 360, 179-189.

12. Gaussian 09, Revision A.01, Frisch M.J., Trucks G.W., Schlegel H.B., Scuseria G.E., Robb M.A., Cheeseman J.R., Scalmani G., Barone V., Mennucci B., Petersson G.A., Nakatsuji H., Caricato M., Li H., Hratchian H.P., Izmaylov A.F., Bloino J., Zheng G., Sonnenberg J.L., Hada M., Ehara M., Toyota K., Fukuda R., Hasegawa J., Ishida M., Nakajima T., Honda Y., Kitao O., Nakai H., Vreven T., Montgomery J.A., Jr., Peralta J.E., Ogliaro F., Bearpark M., Heyd J.J., Brothers E., Kudin K.N., Staroverov V.N., Kobayashi R., Normand J., Raghavachari K., Rendell A., Burant J.C., Iyengar S.S., Tomasi J., Cossi M., Rega N., Millam J.M., Klene M., Knox J.E., Cross J.B., Bakken V., Adamo C., Jaramillo J., Gomperts R., Stratmann R.E., Yazyev O., Austin A.J., Cammi R., Pomelli C., Ochterski J.W., Martin R.L., Morokuma K., Zakrzewski V.G., Voth G.A., Salvador P., Dannenberg J.J., Dapprich S., Daniels A.D., Farkas O., Foresman J.B., Ortiz J.V., Cioslowski J., Fox D.J., Gaussian, Inc., Wallingford CT, 2009.

13. Chachkov D.V., Mikhailov O.V. Russ. J. Inorg. Chem. 2011, 56, 223-231.

14. Chachkov D.V., Mikhailov O.V. Russ. J. Inorg. Chem. 2011, 56, 1935-1942.

15. Ochterski J.W. Thermochemistry in Caussian. Gaussian, Inc., Wallingford CT, 2000.

16. Mikhailov O.V. J. Sol-Gel Sci. Technol. 2014, 72, 314-327. 